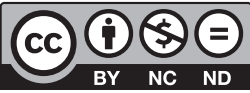

Estudos Teológicos foi licenciado com uma Licença Creative Commons Atribuição - NãoComercial - SemDerivados 3.0 Não Adaptada

http://dx.doi.org/10.22351/et.v59i1.3379

\title{
O CUIDAdO DIANTE DAS INJUSTIÇAS: UMA ANÁLISE SOBRE A PRÁXIS DA POIMÊNICA E DO ACONSELHAMENTO PASTORAL NA RELAÇÃO COM O CONTEXTO LATINO-AMERICANO ${ }^{1}$
}

\author{
Care in face of injustice: \\ An analysis of the praxis of pastoral care and counseling \\ in relation to the Latin American context
}

\section{João Henrique Stumpf ${ }^{2}$ Nilton Eliseu Herbes ${ }^{3}$}

\begin{abstract}
Resumo: O presente artigo se propõe a analisar a práxis da poimênica e do aconselhamento pastoral na relação com o contexto social, político, econômico e cultural latino-americano, identificando suas principais características dentro dos respectivos ramos eclesiais, onde ela é refletida e exercitada. A análise demonstrou, em termos gerais, que a poimênica e o aconselhamento pastoral enfrentam inúmeras dificuldades para assumir o contexto social, político, religioso e até mesmo cultural, como parte de sua missão. Sua orientação individualista e reducionista impede que se aliem às lutas por libertação em andamento no continente. Facilmente adquirem uma característica paliativa ao isolar o indivíduo do contexto histórico no qual está inserido. Boa parte dessas dificuldades está ligada à sua excessiva dependência de modelos e pressupostos estadunidenses e europeus.
\end{abstract}

Palavras-chave: Poimênica. Aconselhamento pastoral. Contexto latino-americano.

Abstract: This article proposes to analyze the praxis of pastoral care and pastoral counseling, in relation to the Latin American social, political, economic and cultural context, identifying its main characteristics within the respective ecclesial branches,

1 O artigo foi recebido em 06 de julho de 2018 e aprovado em 29 de setembro de 2018 com base nas avaliações dos pareceristas ad hoc.

O presente artigo tem como base parte de uma dissertação de mestrado, revisada, atualizada, discutida e aprofundada: STUMPF, João Henrique. Entre o consolo e a profecia: poimênica da libertação diante de desafios pastorais contemporâneos. 2017. 154 p. Dissertação (Mestrado) - Programa de Pós-Graduação, Faculdades EST, São Leopoldo, 2017. Disponível em: <http://dspace.est.edu.br:8080/jspui/bitstream/ BR-SlFE/767/1/stmpf_jh_tm332.pdf>.

2 Mestre em Teologia Prática pela Faculdades EST, São Leopoldo, Rio Grande do Sul, onde atualmente realiza pesquisa de doutorado com o apoio da Igreja da Noruega. Contato: joaohenriques131@gmail.com

3 Doutor em Teologia pela Augustana-Hochschule Neuendettelsau, Alemanha. Professor de Teologia Prática na Faculdades EST, São Leopoldo, Rio Grande do Sul. Contato: nherbes@yahoo.com.br 
where it is reflected and exercised. The analysis has shown in general terms that pastoral care and counseling face numerous difficulties in taking on the social, political, religious and even cultural context as part of their mission. Their individualistic and reductionist orientation prevents them from joining the ongoing struggles for liberation on the continent. They easily acquire a palliative characteristic by isolating the individual from the historical context in which he or she is inserted. Much of these difficulties are linked to their excessive reliance on US and European models and assumptions.

Keywords: Poimenics. Pastoral Counseling. Latin American Context.

\section{Considerações iniciais}

Dados recentes da Comissão Econômica para a América Latina e o Caribe (CEPAL) afirmam que a América Latina e Caribe continua sendo a região economicamente mais desigual do mundo, mesmo após uma década de redução de desigualdades sociais. ${ }^{4}$ Outro relatório da mesma comissão afirma que a pobreza e a miséria voltaram a crescer substancialmente na América Latina alcançando 30,7\% da população. ${ }^{5}$ Além das injustiças econômicas e sociais, devem ser ressaltadas as de ordem cultural e política, sofridas especialmente pelos povos originários, pessoas homoafetivas, populações afrodescendentes, migrantes, pobres socioeconômicos, mulheres e tantos outros grupos e pessoas. Esse contexto desafia as igrejas cristãs em todos os seus setores, dimensões e expressões, pois nega categoricamente a vida doada por Deus a cada pessoa. Suas ações precisam ser pensadas e/ou repensadas com vistas ao contexto no qual estão inseridas. Nesse horizonte amplo, a poimênica é especialmente desafiada a compreender sua missão, uma vez que seu foco é esse ser humano por vezes oprimido pelas injustiças estruturais. Para que isso aconteça é fundamental uma análise crítica que investigue a práxis da poimênica e do aconselhamento pastoral (AP) na relação com o contexto latino-americano. É justamente isso que o presente artigo se propõe a fazer.

Para alcançar tal objetivo o artigo se propõe, no primeiro momento, apresentar e discutir uma análise panorâmica sobre a poimênica e o aconselhamento pastoral no contexto eclesial geral, latino-americano, para posteriormente adentrar as especificidades de cada contexto eclesial. Sem almejar fazer uma análise exaustiva da realidade da práxis da poimênica e aconselhamento pastoral na América Latina (AL), o artigo busca identificar alguns aspectos que evidenciam a relação entre a poimênica e o contexto social, político, econômico e cultural latino-americano.

4 NAÇÕES UNIDAS NO BRASIL. América Latina e Caribe é região mais desigual do mundo, revela comissão da ONU. ONUBR. 2018. Disponível em: $<$ https://nacoesunidas.org/america-latina-e-caribe-eregiao-mais-desigual-do-mundo-revela-comissao-da-onu/>. Acesso em: 14 set. 2018.

5 NAÇÕES UNIDAS NO BRASIL. CEPAL: pobreza aumenta na América Latina e alcança 30,7\% da população. ONUBR. 2017. Disponível em: $<$ https://nacoesunidas.org/cepal-pobreza-aumenta-na-americalatina-e-alcanca-307-da-populacao/>. Acesso em: 21 ago. 2018. 


\section{Panorama sobre a poimênica e o aconselhamento pastoral latino- -americano}

O teólogo protestante Christoph Schneider-Harpprecht sustentava, em um artigo publicado originalmente em 1998, com reedição em 2011, que o aconselhamento pastoral na América Latina ainda era caracterizado pelo sistema de penitência e poimênica sacramental, experimentando dimensões e enfoques mais comunitários especialmente nas vivências das comunidades eclesiais de base (CEBs). ${ }^{6} \mathrm{Na}$ mesma direção, Lothar C. Hoch afirmou em artigo publicado em 1989 que a realidade da poimênica, especialmente no contexto protestante, foi e continuava sendo influenciada por teologias procedentes da Europa e dos Estados Unidos. ${ }^{7}$ Para ele, nesses contextos, o aconselhamento pastoral foi historicamente compreendido como a orientação e o acompanhamento a pessoas com necessidades individuais. ${ }^{8}$ Neste sentido, tais modelos e pressupostos individualistas, oriundos de contextos bastantes dissonantes da América Latina, marcaram profundamente a poimênica ao longo dos anos em nosso continente, fazendo com que a poimênica ignorasse o contexto histórico no qual estavam inseridas as pessoas com as quais se preocupou. ${ }^{9}$

Schneider-Harpprecht lembra que nos bastidores dos modelos oficiais de aconselhamento pastoral importados de outras culturas, de acordo com a história na América Latina, existiram modelos poimênicos provindos de uma religiosidade popular muito difundida no meio do povo, como benzeduras, bênçãos, rezas fortes e outras ações terapêuticas. ${ }^{10} \mathrm{O}$ que Schneider-Harpprecht deduz é que a presença desses modelos e práticas alternativas é indício e consequência de padrões importados de poimênica que não conseguem dialogar de forma efetiva com a cultura popular latino-americana. ${ }^{11}$ Neste sentido pode-se entender sua percepção: "Parece que a maioria das formas de aconselhamento oficial não atinge a dimensão da cultura popular"12. Hoch avançou nessa crítica ao afirmar que as características individualistas dessa poimênica impediram que as ações correspondentes dos agentes religiosos pudessem ser instrumentos proféticos de denúncia contra estruturas sociais, econômicas, políticas, culturais e religiosas opressoras. ${ }^{13}$

Rebeca Radillo, numa reflexão mais atual, aponta na mesma direção de Hoch, ao sustentar que no campo psicoterapêutico os problemas sociais são frequentemente vistos como resultado direto e exclusivo dos problemas internos, enquanto no ambien-

6 SCHNEIDER-HARPPRECHT, Christoph; ZWETSCH, Roberto E. (Orgs.). Teologia prática no contexto da América Latina. 3. ed. revista e ampliada. São Leopoldo: Sinodal, 2011. p. 266.

7 HOCH, Lothar Carlos. Aconselhamento pastoral e libertação. Estudos Teológicos, v. 29, n. 1, p. 17-40, 1989. p. 25-26.

8 HOCH, 1989, p. 25-26.

9 HOCH, 1989, p. 25-26.

10 SCHNEIDER-HARPPRECHT; ZWETSCH, 2011, p. 266.

11 SCHNEIDER-HARPPRECHT; ZWETSCH, 2011, p. 266.

12 SCHNEIDER-HARPPRECHT; ZWETSCH, p. 266.

${ }_{13} \mathrm{HOCH}, 1989$, p. 25-26. 
te teológico os pobres e marginalizados são encarados, por vezes, como pecadores que experimentam sofrimentos devido à falta de espiritualidade. Radillo conclui sua análise afirmando que ambas as comunidades experimentam uma espécie de miopia ao limitarem a causa dos problemas à dimensão subjetiva e/ou intrapsíquica, ignorando as causas sociais, estruturais, de vários problemas subjetivos. ${ }^{14}$ Ora, esse reducionismo - além de equivocado - é uma expressão grave do desconhecimento do que vem a ser aconselhamento pastoral e poimênica no sentido evangélico libertador. Com vistas a alcançarmos maior precisão na análise, torna-se necessário compreendermos a práxis da poimênica e do aconselhamento pastoral dentro de contextos eclesiais específicos, presentes no cenário latino-americano, primeiro identificando e depois analisando criticamente seus respectivos enfoques.

\section{Poimênica e aconselhamento pastoral no contexto da Igreja Católica Apostólica Romana (ICAR)}

Apesar do decréscimo numérico significativo experimentado nos últimos anos pela ICAR ${ }^{15}$, a América Latina ainda é o continente onde o catolicismo aparece com maior força em todo o mundo. Mais de um terço de seus fiéis residem no continente. ${ }^{16}$

Hoch assegura que a ICAR, com seu modelo hierárquico e dogmático, a qual se entendeu, historicamente, como a única despenseira da salvação, influenciou fortemente a práxis da poimênica praticada no seu âmbito, embora não a determinou completamente. ${ }^{17}$ Seu modelo marcado pela rigidez fez com que ela tivesse dificuldades em ser parceira daquelas pessoas que nela procuravam uma instituição acolhedora que pudesse acompanhá-las em seus momentos de crise e frustrações através de um relacionamento pastoral franco e aberto. ${ }^{18}$

14 RADILLO. Rebeca M. Cuidado pastoral con la población urbana pobre: retos y oportunidades. In: SCHIPANI, Daniel S. (Ed.). Nuevos caminos en psicología pastoral: ensayos en homenaje a Jorge A. León. Buenos Aires: Kairós, 2011. p. 111.

15 “O catolicismo está perdendo força na América Latina. Em quatro décadas - entre 1970 e 2014 -, os católicos, que representavam $92 \%$ da população na região, agora são $69 \%$, segundo pesquisa divulgada nesta quinta-feira pelo instituto Pew Research, de Washington, nos Estados Unidos. Nesse mesmo período, a proporção de protestantes passou de $4 \%$ para $19 \%$ da população, com o crescimento das igrejas evangélicas na região e a procura por experiências religiosas mais pessoais. Também aumentou o número de pessoas sem filiação religiosa - que se declaram ateias, agnósticas ou nada em particular -, passando de $0 \%$ para 8\%." FAUS, Joan. Catolicismo perde força e um em cada cinco é protestante na América Latina. Disponível em: <http://brasil.elpais.com/brasil/2014/11/13/internacional/1415854297_029972. html>. Acesso em: 21 mar. 2016.

16 ARAGÃO, Jarbas. Número de católicos na América Latina continua em queda. Disponível em: <https:// noticias.gospelprime.com.br/numero-catolicos-america-latina-queda/>. Acesso em: 21 mar. 2016.

17 Apesar da ICAR ter uma estrutura fortemente hierárquica e dogmática, as CEBs são um exemplo de que o clero católico e as estruturas não conseguem determinar o que acontece na base. As comunidades eclesiais de base conseguiram construir e articular um ministério da poimênica com características comunitárias.

$18 \mathrm{HOCH}, 1989$, p. 19. 
No centro daquilo que se poderia entender como "aconselhamento pastoral" sempre esteve o sacramento, principalmente a confissão e a unção dos enfermos. Esse fato se constituiu possivelmente no motivo pelo qual, através dos séculos, não se desenvolvesse no interior do catolicismo latino-americano uma disciplina como o Aconselhamento Pastoral, que tenha a seu encargo a tarefa de capacitar lideranças para um diálogo pastoral solidário com as pessoas em situações de crise. ${ }^{19}$

Esse quadro mudou significativamente com o Concílio Vaticano II, o qual impulsionou a teologia pastoral nas comunidades católicas. Hoch lembra que a partir de então, e principalmente com a maior participação dos leigos na vida da igreja, surgiram diversas pastorais que protagonizaram uma valorização da poimênica no contexto da ICAR. ${ }^{20}$ Tais pastorais conseguiram desenvolver e articular com mais profundidade a prática do aconselhamento pastoral no contexto do catolicismo. No entanto, não foi possível encontrar em meio a elas um conceito objetivo de aconselhamento pastoral que lhe pudesse servir de fundamento comum.

Para Hoch, evidentemente até a data da edição do artigo citado, a ICAR não tinha atentado para a necessidade de investir em publicações na área do aconselhamento pastoral. ${ }^{21}$ Os anos 1990 parecem indicar alguns avanços nessa direção. A publicação do Dicionário Interdisciplinar da Pastoral da Saúde, publicado em 199922, presume um aumento na preocupação de setores da ICAR com a área da poimênica de modo geral. Apesar disso, para Nelcy T. Zwirtes, teóloga católica brasileira, "o aconselhamento pastoral é pouco conhecido na Igreja Católica latino-americana"23. Atualmente, permanece uma escassez de matérias publicados na área. Zwirtes assegura que ao passo que o AP foi, em boa parte, negligenciado, a direção espiritual recebeu a maior atenção dessa igreja ${ }^{24}$ : “A tarefa de ajudar pessoas assoberbadas por problemas existenciais, emotivos e espirituais não encontrou a mesma atenção na Igreja Católica como a direção espiritual e foi confiada às disposições naturais e à boa vontade dos agentes de pastoral" 25 . O prejuízo da ênfase à direção e orientação espiritual é que tal método não consegue dialogar com a realidade vivenciada pelo povo em geral, conforme lembra Zwirtes: "Verificamos que a experiência da prática de direção e da orientação espiritual contempla mais as pessoas de vida religiosa e sacerdotal ou em

${ }^{19} \mathrm{HOCH}, 1989$, p. 20.

20 “As pastorais são tentativas orientadas pela prática que visam estender a ação da igreja a diferentes grupos humanos ou a realidades conflitivas específicas. Dentre essas pastorais, as que se situam mais próximas ao Aconselhamento Pastoral são a 'Pastoral do Idoso', a 'Pastoral da Família' e, particularmente, a ‘Pastoral da Saúde"”. HOCH, 1989, p. 20.

${ }^{21} \mathrm{HOCH}, 1989$, p. 20.

${ }^{22}$ CINÀ, Giuseppe. Dicionário interdisciplinar da pastoral da saúde. São Paulo: Paulus; Centro Universitário São Camilo, 1999.

${ }^{23}$ ZWIRTES, Nelcy Teresinha. Aconselhamento pastoral com jovens de periferia pobre. 2000. $152 \mathrm{fl}$. Dissertação (Mestrado em Teologia) - Programa de Pós-Graduação em Teologia, Faculdades EST, São Leopoldo, 2000. p. 109.

${ }^{24}$ ZWIRTES, 2000, p. 109-110.

${ }^{25}$ ZWIRTES, 2000, p. 110. 
formação. Esta experiência não consegue atingir e responder a realidade dos jovens empobrecidos e ao povo em geral" 26 .

A ênfase dada pela Igreja Católica na direção e orientação espiritual ${ }^{27}$, a qual objetiva o crescimento espiritual da pessoa ${ }^{28}$, e sua negligência quanto a um aconselhamento pastoral que levasse em consideração o contexto integral no qual as pessoas estão inseridas indicam que a mesma não foge à regra da orientação individualista que caracterizou e ainda, parece, caracterizar a poimênica e o aconselhamento pastoral na AL. Em suma, podemos constatar que o acompanhamento pastoral católico foi marcado pela atenção aos aspectos interiores e espirituais das pessoas ${ }^{29}$, negligenciando as questões de ordem estrutural. ${ }^{30}$

\section{Aconselhamento pastoral e poimênica no contexto do protestantismo de imigração}

Segundo a análise de Hoch, nos espaços institucionais do protestantismo de imigração o aconselhamento pastoral é uma prática conhecida, praticada nas comunidades e também valorizada na maioria dos centros de formação teológica. Nesse âmbito, meio do qual a Igreja Evangélica de Confissão Luterana no Brasil - IECLB faz parte, já foram traduzidas várias obras para o português com o intuito de subsidiar a preparação de ministros e ministras para o aconselhamento pessoal e comunitário. Neste sentido, destacam-se as obras do norte-americano Howard Clinebell, dos holandeses H. Faber e Edel Van der $\operatorname{Schot}^{31}$, além de obras latino-americanas mais atuais. ${ }^{32}$

Um dos principais teóricos que influenciaram a práxis da poimênica nesse contexto continua sendo Howard Clinebell. Sua importância no âmbito do protestantismo histórico é tamanha que sua principal obra traduzida para o português, "Aconselhamento pastoral: modelo centrado em libertação e crescimento", chegou à $6^{\mathrm{a}}$ edição em 2016. O modelo poimênico construído por Clinebell parte da noção do ser humano criado à imagem e semelhança de Deus como um ser integral. Desta forma, a poimê-

26 ZWIRTES, 2000, p. 125.

27 A direção espiritual foi assumida especialmente pelo movimento Renovação Carismática, que atualmente mantém o programa Direção Espiritual, que vai ao ar semanalmente, apresentado pelo padre Fábio de Melo, uma das figuras mais conhecidas do movimento. "O programa ajuda o telespectador a refletir sobre situações do cotidiano que precisam de visão espiritual e de mudança de vida”. CANÇÃO NOVA. Direção Espiritual. 2018. Disponível em: < https://tv.cancaonova.com/programa/direcao-espiritual/>. Acesso em: 27 jun. 2018.

28 ZWIRTES, 2000, p. 112.

29 ZWIRTES, 2000, p. 125.

${ }^{30}$ Tal análise não leva em conta as realidades ligadas às CEBs que contrastam fortemente com tal orientação individualista.

31 HOCH, 1989, p. 21.

32 SCHIPANI, Daniel S. O Caminho da Sabedoria no Aconselhamento Pastoral. São Leopoldo: Sinodal, 2013; SANTOS, Hugo N. (ed.). Dimensões do Cuidado e Aconselhamento Pastoral: Contribuições a partir da América Latina e Caribe. São Paulo: ASTE; São Leopoldo: CETELA, 2018. 
nica e o aconselhamento pastoral devem buscar ajudar as pessoas a desenvolverem todas as suas potencialidades, priorizando a integridade espiritual e ética: ${ }^{33}$

O objetivo abrangente de toda poimênica e de todo aconselhamento pastoral (e de todo ministério) é libertar, potencializar e sustentar a integridade centrada no Espírito. Os métodos de poimênica e de aconselhamento são importantes dimensões desse ministério possibilitadores de integridade ${ }^{34}$.

O modelo proposto por Clinebell supera parte da orientação individualista que marca a poimênica latino-americana quando expande a responsabilidade desse ministério também ao sacerdócio geral de todas as pessoas crentes, permanecendo como tarefa de ministros e ministras a função de "treinar, inspirar e supervisionar as pessoas leigas no ministério de poimênica, usando, ao mesmo tempo, também os fecundos recursos de sua formação, de seu papel profissional e de seu ofício pastoral na execução de seu próprio trabalho de poimênica" 35 . Schneider-Harpprecht define assim os pontos positivos do modelo de Clinebell:

O modelo de Clinebell abriu-se para impulsos da psicologia humanística, porém tenta fundamentá-la biblicamente. Uma visão aberta para o pluralismo religioso nas sociedades modernas, a ênfase no aspecto comunitário, a sensibilidade para os problemas causados pelo sexismo e a injustiça social nas cidades do norte e na relação norte-sul do planeta aproximam esta concepção das necessidades da realidade latino-americana ${ }^{36}$.

Schneider-Harpprecht, por outro lado, questiona alguns aspectos do método de Clinebell:

A pergunta central em relação a qualquer concepção holística é se ela realmente leva a sério que a vida é sempre um fragmento, que não é a plenitude da presença de Deus, mas a experiência da ausência de sentido frente à morte, ao sofrimento e à injustiça, a experiência da carência de ser que domina o ser humano e faz com que ele, como ser falante, esteja sempre a caminho, em busca de sentido e de um futuro diferente ${ }^{37}$.

Em todo caso, o método de Clinebell representou avanços significativos para a poimênica latino-americana no âmbito do protestantismo histórico. Clinebell percebe com clareza a necessidade de pensarmos uma poimênica e um aconselhamento pastoral que levem em consideração as opressões estruturais sofridas pelas pessoas atendidas ao mencionar a quinta dimensão da integralidade: "Não pode haver integralidade plena ou duradoura para indivíduos e famílias num mundo quebrantado, num mundo

${ }^{33}$ CLINEBELL, Howard J. Aconselhamento pastoral: modelo centrado em libertação e crescimento. 4. ed. São Leopoldo: EST; Sinodal, 2007. p. 25.

${ }^{34}$ CLINEBELL, 2007, p. 25.

${ }^{35}$ CLINEBELL, 2007, p. 33.

${ }^{36}$ SCHNEIDER-HARPPRECHT; ZWETSCH, 2011, p. 269-270.

37 SCHNEIDER-HARPPRECHT; ZWETSCH, 2011, p. 270. 
que destrói integralidade através de seus sistemas de injustiça, pobreza, violência e exploração" ${ }^{38}$. Mesmo representando avanços significativos, os pressupostos teóricos de Clinebell permanecem marcados por sua realidade específica, o que dificulta a aceitação de seu método na América Latina, ainda que ajude na busca de um caminho próprio em nosso contexto.

Conforme assinala Hoch, que expressa tal análise cerca de dois anos após a primeira edição da obra de Clinebell ${ }^{39}$ em português, a poimênica latino-americana dentro do protestantismo, embora influenciada positivamente pelos pressupostos defendidos pelo teólogo norte-americano, ainda não tinha conseguido assumir a realidade do continente de forma suficientemente séria. Seus pressupostos importados de contextos bem específicos dificultam o diálogo com as realidades do nosso continente. Hoch entende que, para a poimênica no contexto do protestantismo de imigração, "o maior desafio consiste em desenvolver um conceito de Aconselhamento Pastoral que leve em conta a realidade latino-americana" ${ }^{40}$.

\section{Aconselhamento pastoral e poimênica no contexto do protestantismo de missão}

Assim como no protestantismo de imigração, no protestantismo de missão o aconselhamento pastoral é uma disciplina valorizada nos currículos de seus respectivos seminários. Hoch salienta que uma das primeiras publicações que atesta a importância que o aconselhamento vem ganhando nesse meio é a obra ${ }^{41}$ de V. James Mannoia. ${ }^{42} \mathrm{Na}$ referida obra, o pastor e doutor em Filosofia ${ }^{43}$ desenvolve e articula o campo da psicologia aplicada com vistas à solução dos problemas individuais, ou seja, busca aplicar um ramo da psicologia à práxis do aconselhamento pastoral. ${ }^{44}$ Outro representante no âmbito desse protestantismo é o psicólogo norte-americano Gary R. Collins, com várias obras traduzidas ao português, que assim define o que entende por aconselhamento pastoral:

O aconselhamento pastoral emprega vários métodos de cura para ajudar as pessoas a enfrentarem seus problemas de uma forma coerente com os ensinamentos bíblicos. $\mathrm{O}$ objetivo final é que os aconselhandos cheguem à cura, aprendam a lidar com situações semelhantes e experimentem crescimento espiritual ${ }^{45}$.

\footnotetext{
${ }^{38}$ CLINEBELL, 2007, p. 31.

39 CLINEBELL, Howard J. Aconselhamento pastoral: modelo centrado em libertação e crescimento. São Paulo: Paulinas; São Leopoldo: Sinodal, 1987.

40 HOCH, 1989, p. 22.

${ }^{41}$ MANNÓIA, V. James. Aconselhamento pastoral. São Paulo: Palavras da Cruz, 1981.

42 HOCH, 1989, p. 22.

43 MANNÓIA, 1981, p. 9.

44 MANNÓIA, 1981, p. 51-113.

${ }^{45}$ COLLINS, Gary R. Aconselhamento cristão: edição século 21. São Paulo: Vida Nova, 2004. p. 17.
} 
Um dos problemas da proposta de Collins é sua maneira de direcionar o aconselhamento para a cura através do uso da Bíblia. Sua abordagem não leva em consideração o fato de que a Bíblia não é um manual para a solução dos problemas humanos. Ainda assim, chama a atenção no âmbito do protestantismo de missão o crescimento do uso da psicologia pastoral, conforme destaca Hoch: "Junto com o Aconselhamento Pastoral observa-se uma crescente valorização da Psicologia Pastoral entre as igrejas do protestantismo histórico" "46. Apesar desse avanço no uso da psicologia, Hoch alerta para o fato da mesma se mostrar extremamente dependente dos teóricos norte-americanos, não conseguindo tomar seriamente em consideração a realidade latino-americana, reafirmando assim uma prática individualista, que ignora o contexto no qual as pessoas vivem ${ }^{47}$, com suas carências, dificuldades objetivas e maneiras peculiares de ver o mundo. Schneider-Harpprecht, analisando o modelo evangelical de psicologia pastoral presente no meio do protestantismo de missão, ressalta: “Apesar da orientação comunitária e do forte engajamento na questão da família, o modelo não fornece instrumentos para um trabalho que inclua o contexto social e político de pobreza e marginalização"48.

A realidade tanto da poimênica como do AP nessa ramificação do protestantismo aponta carências principalmente na área de sua contextualização. Seus modelos e pressupostos, fortemente dependentes dos teóricos norte-americanos, com ênfase individualista, dificultam a construção de uma poimênica que leve efetivamente o contexto latino-americano a sério.

\section{Aconselhamentopastoralepoimênicanocontextodopentecostalismo}

As igrejas pentecostais tiveram um crescimento espantoso nas últimas décadas em todo o mundo, mas principalmente na América Latina e Caribe. O ambiente responsável pelo seu crescimento é composto basicamente pelas camadas mais pobres da população ${ }^{49}$, crescendo nos últimos anos sua presença nas camadas médias e médias altas. Para Hoch, uma das causas desse extraordinário crescimento numérico se localiza na ênfase sobre a prática da cura e milagres entre as classes sociais mais baixas. Para esse autor, essa é a base onde se localiza a concepção implícita que tais igrejas têm a respeito do aconselhamento pastoral e da poimênica. ${ }^{50}$

O meio pentecostal pauta sua práxis poimênica em uma hermenêutica literalista da Bíblia. Uma das principais obras utilizadas nesses círculos, segundo Hoch ${ }^{51}$, é a de Jay Adams $^{52}$, a qual sustenta a necessidade do cristão utilizar basicamente a

$46 \mathrm{HOCH}, 1989$, p. 21.

$47 \mathrm{HOCH}, 1989$, p. 22.

48 SCHNEIDER-HARPPRECHT; ZWETSCH, 2011, p. 269.

$49 \mathrm{HOCH}, 1989$, p. 22.

$50 \mathrm{HOCH}, 1989$, p. 22.

51 HOCH, 1989, p. 22.

52 ADAMS, Jay E. Conselheiro capaz. São Paulo: Fiel, 1977. 
Bíblia como uma espécie de manual para a condução da vida. ${ }^{53}$ Com isso, Adams faz oposição à utilização de outras disciplinas e ciências humanas para aperfeiçoar o processo poimênico. ${ }^{54} \mathrm{~A}$ visão de Adams não é unânime em relação ao método do aconselhamento pastoral no âmbito do pentecostalismo. Wayde I. Goodall, um dos pesquisadores mais respeitados da área nesse âmbito, a partir do entendimento de que toda verdade provém de Deus, justifica a utilização e apropriação de áreas de conhecimento e terapias conhecidas como seculares, quando essas dão testemunho da verdade de Deus:

Se um médico, mediante sua perícia, pode ajudar alguém, então devíamos ser-lhe gratos por isso. Agradeça a Deus sempre que a sua verdade é descoberta. Se os indivíduos que procuramos ajudar precisam de atenção médica, devíamos enviá-los a um competente médico. Se precisam de ajuda psiquiátrica, devíamos incentivá-los a trabalhar com um psiquiatra que desse aconselhamento sem violar as convicções religiosas do cliente. Toda verdade pertence a Deus, e nós lhe agradecemos por isso ${ }^{55}$.

Tanto para Goodall como para Adams o fundamento insubstituível do AP é a Bíblia. Afirma Adams: "Aconselhamento feito sem as Escrituras só se pode esperar que será aconselhamento sem o Espírito Santo" ${ }^{\circ 6}$. Goodall aponta na mesma direção: "Não importa o que os sentimentos ou as emoções indicam, nunca é apropriado aconselhar algo contrário à Palavra de Deus. [...] $\mathrm{O}$ crente sempre deve obedecer às Escrituras ao fazer o aconselhamento" ${ }^{57}$. Ambas as compreensões sobre o aconselhamento pastoral têm em comum seu embasamento numa hermenêutica literalista ou fundamentalista da Bíblia.

Schneider-Harpprecht define os objetivos e fundamentos do modelo de aconselhamento em Adams nestes termos:

O aconselhamento quer levar a pessoa à salvação através da morte do "velho homem" e da ressurreição para um novo modo de vida seguindo Jesus Cristo e agindo conforme as regras divinas de comportamento humano que são descritas na Bíblia. A Bíblia, que é verbalmente inspirada, revela em todas as suas partes a verdade de Deus e oferece ao ser humano pecador regras para conduzir a vida. Ele mostra como a desobediência em relação a Deus cria todo o sofrimento e a doença nos seres humanos ${ }^{58}$.

53 Torna-se importante ressaltar que Adams é usado também por teologias evangélicas conservadoras. Apesar do livro referenciado ter sido lançado por uma editora evangélica tradicional, o mesmo foi adotado também por correntes evangelicais que adotam uma leitura fundamentalista da Bíblia.

54 ADAMS, 1977, p. 9.

${ }^{55}$ GOODALL, Wayde I. O que é aconselhamento bíblico? In: CARLSON, Raymond et al. O pastor pentecostal: teologia e práticas pastorais. Rio de Janeiro: CPAD, 2005. p. 568.

56 ADAMS, 1977, p. 40.

57 GOODALL, 2005, p. 567.

${ }^{58}$ SCHNEIDER-HARPPRECHT, Christoph. Aconselhamento Pastoral. In: SCHNEIDER-HARPPRECHT, Christoph. (Org.). Teologia prática no contexto da América Latina. 2. ed. São Leopoldo: Sinodal; São Paulo: ASTE, 2005. p. 303. 
Com base nisso, o aconselhamento pastoral no meio pentecostal consiste num chamado ao arrependimento, uma vez que a causa do sofrimento reside nos pecados individuais. Também Goodall indica para a mesma direção ao sustentar a santidade como sinônimo da saúde mental: "Quanto mais estáveis as pessoas se tornam como cristãos e quanto mais entendem como aplicar as verdades da Palavra de Deus em suas vidas, melhor será a saúde mental que terão. Viver da maneira como Deus planejou simplesmente dá certo" 59 . O objetivo último do aconselhamento nesse âmbito é a salvação de almas, conforme indica Goodall. ${ }^{60}$

A prioridade da poimênica do aconselhamento pastoral no pentecostalismo está em melhorar o relacionamento do indivíduo com Deus, com vistas à salvação. Assim sendo, o que se pode imaginar é que muitas questões relacionadas com o bem viver neste mundo são negligenciadas, conforme defende Hoch:

Preocupa especialmente a concepção individualista da pessoa humana desses movimentos. No seu ímpeto missionário eles tendem a ignorar a realidade social como causa geradora do sofrimento humano. Doença e miséria são resultado de fracasso e desobediência individuais. Fala-se também em "libertação". Mas esse conceito é entendido primordialmente no sentido moral, como um não contaminar-se com o mundo ${ }^{61}$.

Para Schneider-Harpprecht, o modelo de aconselhamento pastoral predominante nos meios pentecostais se fundamenta na obediência e obrigação, considerando as Escrituras Sagradas como um conjunto de normas e leis transculturais e eternas, as quais dispensam qualquer contextualização. ${ }^{62}$ Sathler-Rosa é categórico ao afirmar a insuficiência da utilização exclusiva da Bíblia para a formação de agentes de cuidado pastoral:

O conhecimento das Escrituras não é por si só suficiente para habilitar pastores, pastoras e outros agentes de cuidado pastoral que acompanham pessoas e famílias na procura por suporte espiritual e emocional em meio aos percalços. A Bíblia é e continua sendo fonte de inspiração e iluminação para o exercício do pastoreio. Entretanto, a contínua ação de Deus na história nutre e renova a existência de homens e mulheres e levanta novos "sinais dos tempos". Reclamam presença profética e pastoral das igrejas. As condições da existência humana em geral e as situações concretas vividas por pessoas, famílias e comunidades devem merecer minucioso estudo e atenção da parte de agentes pastorais ${ }^{63}$.

Neste sentido, a utilização exclusiva da Bíblia na práxis da poimênica e aconselhamento pastoral mostra-se insuficiente na importante tarefa de ler os novos contextos que desafiam o cuidado pastoral como um todo, além de fazer com que o mesmo se feche para a ação criativa de Deus, que se dá ao longo da história.

${ }^{59}$ GOODALL, 2005, p. 564.

${ }^{60}$ GOODALL, 2005, p. 563.

${ }^{61} \mathrm{HOCH}, 1989$, p. 22.

${ }^{62}$ SCHNEIDER-HARPPRECHT, 2005, p. 304.

${ }^{63}$ SATHLER-ROSA, Ronaldo. Cuidado pastoral em perspectiva histórica e existencial: uma revisão crítica. São Paulo: ASTE, 2013. p. 12. 
De modo geral, a poimênica no contexto pentecostal continua sendo marcada por um individualismo que parece permanecer cego às opressões que têm origem em estruturas sociais, políticas, econômicas, religiosas e culturais, além de facilmente esquecer a graça de Deus e a liberdade cristã. ${ }^{64}$

\section{Aconselhamento pastoral e poimênica no contexto do neopentecostalismo}

$\mathrm{Na}$ atualidade, o neopentecostalismo pode ser considerado como o maior movimento eclesial, com base na grande aptidão de mobilização de pessoal, controle sobre vários meios de comunicação de massas e uma capacidade ímpar de captação de recursos financeiros, conforme destaca Paulo Rodrigues Romeiro. ${ }^{65}$

Roberto E. Zwetsch afirma que o segredo do sucesso do neopentecostalismo é a sua oferta de resposta aos problemas cotidianos da sociedade capitalista: o neopentecostalismo "tem se caracterizado por trabalhar a insegurança coletiva das pessoas diante da crise social e econômica que se abate sobre as sociedades latino-americanas e que não encontram resposta nem nas políticas dos governos democráticos, nem nas igrejas dos outros tipos"66. Sua mensagem teológica é baseada na prosperidade em todos os setores da vida: "Sua teologia tem se caracterizado por prometer prosperidade e sucesso na vida, afirmando que Deus não quer o sofrimento de ninguém. Por isto, um de seus lemas mais divulgados é: "Pare de sofrer! Aqui você encontra libertação"' ${ }^{67}$ Por tais fatores a mensagem teológica anunciada pelo neopentecostalismo é bastante tentadora, uma vez que promete resolver todos os problemas da vida. Evidentemente, tal mensagem se torna ainda mais sedutora entre grupos e pessoas que mais sofrem, conforme destaca o pesquisador Leonildo Silveira Campos: "Aos olhos de uma população empobrecida, crédula, em busca de soluções de menos esforço, carente de autoestima e otimismo, a cura divina se apresenta como um meio atraente e irresistível, principalmente aos que se sentem sem luz dentro de um grande túnel" ${ }^{68}$.

Zwetsch chama a atenção para um fator no mínimo interessante: a teologia neopentecostal construiu-se a partir do tema medular da teologia da libertação, a saber, a temática da libertação, lhe atribuindo, porém, uma orientação individualista e focando a interiorização da experiência: "Chama a atenção como neste caso a teologia da igreja se apropriou do tema central da teologia latino-americana de libertação,

${ }^{64}$ SCHNEIDER-HARPPRECHT, 2005, p. 304.

${ }^{65}$ ROMEIRO, Paulo Rodrigues; SILVA, Geoval Jacinto da. Esperanças e decepções: uma análise crítica da prática pastoral do neopentecostalismo na Igreja Internacional da Graça de Deus sob a perspectiva da práxis religiosa. São Bernardo do Campo: Universidade Metodista de São Paulo, Faculdade de Filosofia e Ciências da Religião, 2004. p. 27.

${ }^{66}$ ZWETSCH, Roberto E. Missão como com-paixão: por uma teologia da missão em perspectiva latino-americana. São Leopoldo: Sinodal; Quito: CLAI, 2008. p. 48.

${ }^{67}$ ZWETSCH, 2008, p. 48.

${ }^{68}$ CAMPOS, Leonildo Silveira. Teatro, templo e mercado: organização e marketing de um empreendimento neopentecostal. Petrópolis: Vozes; São Paulo: Simpósio; São Bernardo do Campo: UMESP, 1997. p. 369. 
reinterpretando-o em forma individualista e interiorizando a experiência, encantando desta forma vastos setores da população [...]"69. Em todo caso, a ênfase e a abordagem individualista podem estar sinalizando que o aconselhamento pastoral e a poimênica, embora com orientações teológicas que suscitam dúvidas e que servem a interesses específicos, exercem um papel fundamental dentro desse âmbito eclesial. Zwetsch, mesmo sem utilizar o termo específico do aconselhamento pastoral, parece querer indicar que nesse contexto eclesial o aconselhamento pastoral é uma ferramenta importante para que seus líderes religiosos possam atender as pessoas que buscam ajuda espiritual ou em algum outro setor de sua vida:

[...] este tipo de igreja procura se fazer acessível a um público cotidiano e flutuante, razão pela qual normalmente está com suas portas abertas, ao nível da calçada e sempre com muitas pessoas prontas a atender quem busca alguma ajuda espiritual ou de outra natureza ${ }^{70}$.

Com a forte incidência sobre as mídias e demais meios de comunicação de massa, o movimento neopentecostal consegue estabelecer meios para atendimento a pessoas com problemas nas mais variadas áreas de suas vidas, em alguns casos até $24 \mathrm{~h}$ por dia. São muitas as iniciativas presentes nesse meio que buscam aproximar a relação entre pessoas atormentadas por problemas de toda sorte com obreiros da igreja. A Igreja Universal do Reino de Deus (IURD), por exemplo, mantêm no ar 24h por dia o Pastor On Line, um programa que visa dar orientação espiritual para pessoas atribuladas, por meio de telefone e internet, conforme a chamada no site: "Por meio do Pastor Online as pessoas que buscam ajuda recebem uma palavra de orientação espiritual para suas vidas $[\ldots]^{\prime \prime 71}$.

Muitas outras denominações neopentecostais disponibilizam recursos semelhantes para oferecer orientações para os fiéis através de programas de televisão, rádio, internet e outros. As mídias de massa são os principais canais pelos quais as orientações pastorais chegam até as pessoas, mesmo assim a grande maioria das denominações desse ramo mantém as portas de suas igrejas abertas o dia todo para atendimentos pessoais individuais.

Os pressupostos teológicos que balizam o aconselhamento pastoral nesse ramo eclesial seguem as coordenadas da teologia da prosperidade. Os problemas enfrentados pelas pessoas são geralmente interpretados como resultados da falta de fé ou da ação de demônios e entidades. "Segundo R. R. Soares, o poder das entidades

69 ZWETSCH, 2008, p. 48. Tal constatação pode estar nos indicando que uma falha histórica fundamental da TdL e que lhe impediu de ganhar mais espaço entre as classes menos favorecidas foi justamente sua negligência em relação aos fatores subjetivos íntimos da libertação. Tal tese já foi sustentada por Lothar Carlos Hoch em seu artigo "Comunidade terapêutica: em busca duma fundamentação eclesiológica do aconselhamento pastoral”. SCHNEIDER-HARPPRECHT, Christoph (Org.). Fundamentos teológicos do aconselhamento. São Leopoldo: Sinodal, 1998. p. 24.

70 ZWETSCH, 2008, p. 49.

71 Informações complementares sobre esse programa pode ser encontrado no site da IURD. Pastor On Line. Disponível em: <http://www.universal.org/pastoronline/>. Acesso em: 22 ago. 2016. 
malignas vai além de causar doenças. Atua também na área financeira, casamento e trabalho"72. Desta forma, o processo poimênico, sob tais pressupostos, foca na prática de exorcismo, oração e a leitura de textos bíblicos. Os trechos bíblicos são, geralmente, interpretados de forma literalista. A integridade da pessoa humana que recorre à ajuda pastoral geralmente é deixada de lado em prol da hegemonia fundamentalista das verdades absolutas. A sensibilidade pastoral necessária para qualquer atendimento fica ausente, uma vez que se tem a noção de que os causadores das atribulações são fatores transcendentes à existência humana. Pode-se afirmar que a práxis do aconselhamento pastoral e da poimênica nesse ramo eclesial não leva em consideração, de forma suficiente, as causas dos sofrimentos vinculadas às realidades sociais, políticas, econômicas e culturais.

Tendo em vista os vários ramos eclesiais analisados, a investigação demonstrou, em termos gerais, que a poimênica e o aconselhamento pastoral enfrentam inúmeras dificuldades para manter um diálogo saudável com o contexto social, político, religioso e cultural, não conseguindo desenvolver uma postura de denúncia profética frente a estruturas, sistemas e lógicas que conferem sofrimento às pessoas. Sua orientação individualista impede que se aliem às lutas por libertação em andamento no continente. Torna-se fundamental a construção e articulação de uma poimênica e um AP que tenham como base os desafios específicos da América Latina. Por questões de delimitação de espaço não será possível desenvolver propostas objetivas para a construção e articulação de um conceito de poimênica e AP que incorpore os desafios latino-americanos.

\section{Considerações finais}

Através deste estudo podemos constatar que dificilmente poderemos falar de uma realidade de aconselhamento pastoral e poimênica do contexto latino-americano numa visão única. A diversidade de religiosidades presente neste continente nos leva a falar de uma realidade com muitas nuanças. No entanto, percebe-se uma característica que marca a práxis da poimênica e do aconselhamento pastoral em todos os ramos eclesiais analisados, a saber, a orientação individualista. Tal característica gera um cuidado pastoral míope às estruturas, lógicas e aos sistemas que conferem sofrimento às pessoas, não conseguindo, por vezes, identificar as causas estruturais de vários problemas subjetivos/pessoais.

O desafio que fica é pensar a partir de um contexto onde se levem mais a sério os aspectos sociais, políticos, religiosos e culturais do povo latino-americano, articulando a práxis de uma poimênica e aconselhamento pastoral sistêmicos, que conseguem compreender o indivíduo dentro do contexto maior do qual ele faz parte, equilibrando o cuidado pessoal com a denúncia das estruturas injustas que conferem sofrimento às pessoas. $\mathrm{O}$ desafio é a construção de uma poimênica que se articule, simultaneamente, entre o consolo e a denúncia profética.

72 ROMEIRO; SILVA, 2004, p. 133. 


\section{Referências}

ADAMS, Jay E. Conselheiro capaz. São Paulo: Fiel, 1977.

ARAGÃO, Jarbas. Número de católicos na América Latina continua em queda. Disponível em: $<$ https://noticias.gospelprime.com.br/numero-catolicos-america-latina-queda/ $>$. Acesso em: 21 mar. 2016.

CAMPOS, Leonildo Silveira. Teatro, templo e mercado: organização e marketing de um empreendimento neopentecostal. Petrópolis: Vozes; São Paulo: Simpósio; São Bernardo do Campo: UMESP, 1997.

CANÇÃO NOVA. Direção Espiritual. 2018. Disponível em: <https://tv.cancaonova.com/programa/direcao-espiritual/>.

CINÀ, Giuseppe. Dicionário interdisciplinar da pastoral da saúde. São Paulo: Paulus; Centro Universitário São Camilo, 1999.

CLINEBELL, Howard J. Aconselhamento pastoral: modelo centrado em libertação e crescimento. 4. ed. São Leopoldo: EST; Sinodal, 2007.

COLLINS, Gary R. Aconselhamento cristão: edição século 21. São Paulo: Vida Nova, 2004.

FAUS, Joan. Catolicismo perde força e um em cada cinco é protestante na América Latina. 2013. El País. Disponível em: <http://brasil.elpais.com/brasil/2014/11/13/internacional/1415854297_029972.html>. Acesso em: 21 mar. 2016.

GOODALL, Wayde I. O que é aconselhamento bíblico? In: CARLSON, Raymond et al. O pastor pentecostal: teologia e práticas pastorais. Rio de Janeiro: CPAD, 2005.

HOCH, Lothar Carlos. Aconselhamento pastoral e libertação. Estudos Teológicos, v. 29, n. 1, p. 17-40, 1989.

MANNÓIA, V. James. Aconselhamento pastoral. São Paulo: Palavras da Cruz, 1981.

RADILLO, Rebeca M. Cuidado pastoral con la población urbana pobre: retos y oportunidades. In: SCHIPANI, Daniel S. (Ed.). Nuevos caminos en psicología pastoral: ensayos en homenaje a Jorge A. León. Buenos Aires: Kairós, 2011.

ROMEIRO, Paulo Rodrigues; SILVA, Geoval Jacinto da. Esperanças e decepções: uma análise crítica da prática pastoral do neopentecostalismo na Igreja Internacional da Graça de Deus sob a perspectiva da práxis religiosa. São Bernardo do Campo: Universidade Metodista de São Paulo, Faculdade de Filosofia e Ciências da Religião, 2004.

SATHLER-ROSA, Ronaldo. Cuidado pastoral em perspectiva histórica e existencial: uma revisão crítica. São Paulo: ASTE, 2013.

SCHNEIDER-HARPPRECHT, Christoph (Org.). Fundamentos teológicos do aconselhamento. São Leopoldo: Sinodal, 1998.

SCHNEIDER-HARPPRECHT, Christoph; ZWETSCH, Roberto E. (Orgs.). Teologia prática no contexto da América Latina. 3. ed. revista e ampliada. São Leopoldo: Sinodal, 2011.

SCHNEIDER-HARPPRECHT, Christoph. Aconselhamento Pastoral. In: SCHNEIDER-HARPPRECHT, Christoph (Org.). Teologia prática no contexto da América Latina. 2. ed. São Leopoldo: Sinodal; São Paulo: ASTE, 2005.

ZWETSCH, Roberto E. Missão como com-paixão: por uma teologia da missão em perspectiva latino-americana. São Leopoldo: Sinodal; Quito: CLAI, 2008.

ZWIRTES, Nelcy Teresinha. Aconselhamento pastoral com jovens de periferia pobre. 2000. 152 fl. Dissertação (Mestrado em Teologia) - Programa de Pós-Graduação em Teologia, Faculdades EST, São Leopoldo, 2000. 